\title{
Processos de significação em um guia de prevenção da violência sexual na infância
}

\author{
Juliana de Castro Santana ${ }^{1}$
}

\begin{abstract}
Resumo: Considerando que sujeitos e sentidos se constituem mutuamente e que a linguagem não é transparente, este estudo, ancorado nos pressupostos da Análise de Discurso, se propõe a analisar os processos discursivos em funcionamento em um guia de prevenção da violência sexual para crianças a partir dos 4 anos. Em função do caráter social da educação e da articulação entre ensino, conhecimento e sociedade, pareceu-nos significativo refletir sobre o modo como o Estado, através das instituições e dos discursos que nelas circulam, administra o complexo processo de significação sobre a violência sexual na infância, produzindo identificações e efeitos de verdade.
\end{abstract}

Palavras-chave: Interpretação. Equívoco. Guia de prevenção da violência sexual.

\begin{abstract}
Considering that subjects and meanings constitute themselves mutually, this study, based on the Discourse Analysis assumptions, aims at analyzing the discursive processes functioning in a material addressed to four-year-old children on sexual violence prevention. Due to the social role that education plays as well as the articulation between teaching, knowledge and society, it is significant to reflect on the way that the State, through its institutions and discourses, administrate the complex signification process on children sexual abuse, producing identifications and effects of truth.
\end{abstract}

Keywords: Interpretation. Equivocity. Sexual violence prevention guidebook.

Resumen: Considerando que sujetos y sentidos se constituyen mutuamente y que el lenguaje no es transparente, este estudio, sostenido en los presupuestos del Análisis de Discurso, se propone analizar los procesos discursivos en funcionamiento en un guía de prevención de la violencia sexual para niños a partir de los 4 años. En función del carácter social de la educación y de la articulación entre enseñanza, conocimiento y sociedad, nos pareció significativo reflexionar sobre el modo en que el Estado, a través de las instituciones y de los discursos que en ellas circulan, administra el complejo proceso de significación sobre la violencia sexual en la infancia, produciendo identificaciones y efectos de verdad.

Palabras clave: Interpretación. Equivocidad. Guía de prevención de la violencia sexual.

\footnotetext{
${ }^{1}$ Professora adjunta, orientadora e pesquisadora no Programa de Pós-Graduação em Ciências da Linguagem da Universidade do Vale do Sapucaí (UNIVÁS). Possui mestrado e doutorado em Linguística Aplicada pela Unicamp e pós-doutorado em Tradução, realizado na mesma universidade.
} 


\section{Introdução}

O objetivo deste estudo, desenvolvido à luz do dispositivo teórico-metodológico da Análise de Discurso (AD), é compreender o complexo processo de significação que está em funcionamento em um livro sobre prevenção da violência sexual na infância. Por meio de suas ilustrações e de seus personagens, este material, endereçado para crianças a partir dos 3 anos de idade, fornece diretrizes para que pais, educadores, profissionais da saúde e do direito possam abordar situações apontadas como sexualmente abusivas na infância. De acordo com informações contidas no site ${ }^{2}$ que divulga e comercializa o material em questão, "Pipo e Fifi é um premiado livro infantil que funciona como uma ferramenta de proteção, explicando às crianças, a partir dos 3 anos de idade, conceitos básicos sobre o corpo, sentimentos, convivência e trocas afetivas". O site em questão, além de divulgar e comercializar os livros de prevenção da violência sexual na infância, também oferece cursos online, palestras e oficinas para um público alvo variado, incluindo profissionais da saúde, da educação e do direito. Ainda segundo informações retiradas do site de divulgação, a autora do livro 3

é pedagoga, especialista em Educação Sexual pelo CESEX-Brasília e Educadora Social com experiência na elaboração e condução de projetos voltados para crianças e adolescentes nas áreas de prevenção de violência sexual. Mestre em Educação Sexual pela Unesp, é consultora da Rede Globo e parceira do programa Encontro com Fátima Bernardes. Além de escrever, atua como presidente do Instituto Cores e como gestora do projeto social Escola de Ser.

As ilustrações deste material, que são essenciais para reforçar o que ele propõe e prescreve através dos personagens e situações retratadas, foram criadas por uma ilustradora que, segundo informações retiradas do site,

é formada em Design Gráfico pela Universidade Estadual de Minas Gerais, trabalha na área de ilustração infanto-juvenil desde 2002. Ilustra revistas como: Atrevida, Decorar Mais por Menos, Atrevidinha, e também livros para as editoras FTD, Pitágoras, Zatti. Foi finalista no concurso de ilustração da Folha de São Paulo, categoria Infantil.

\footnotetext{
2 www.pipoefifi.com.br

${ }^{3}$ Optei por não mencionar os nomes da autora e da ilustradora do material analisado, pois para a $A D$, não é a noção de sujeito enquanto pessoa ou indivíduo que consideramos em nossa análise, mas sim o lugar social do qual se fala e que é relevante para produção de determinados efeitos de sentido.
} 
O livro ${ }^{4}$ Pipo e Fifi já teve mais de 100 mil cópias distribuídas no Brasil. Sua distribuição foi feita em larga escala para um público alvo bastante variado: pais, educadores, profissionais da saúde e do direito, assistentes sociais, familiares, crianças e adolescentes. O material em questão também circulou e ainda circula nas redes sociais, via Facebook e WhatsApp, na versão em PDF e/ou no formato de e-book. Muitos professores de escolas públicas e privadas, em especial os que trabalham com a educação infantil e o ensino fundamental I, tiveram acesso ao referido guia de prevenção 5 .

Neste material que tomamos como objeto de análise e que se apresenta como "um guia de prevenção ou ferramenta de proteção da criança e de seu corpo", interessou-nos observar, dentre outras coisas, como o efeito de evidência discursiva ou de transparência do sentido é produzido.

Considerando que, de acordo com a perspectiva discursiva, a contradição e o equívoco são constitutivos do sujeito e da linguagem, salientamos a importância de atentarmos, sobretudo enquanto educadores, para outras leituras e interpretações que o livro em questão pode suscitar, lembrando que a linguagem, seja ela verbal ou não verbal, é metafórica e ideológica por excelência. Sem perder de vista o caráter social da educação e a articulação entre ensino, conhecimento e sociedade, pareceu-nos significativo refletir sobre o modo como o Estado ${ }^{6}$, através das instituições e discursos que nelas circulam, administra o complexo processo de significação sobre a violência sexual infantil, produzindo identificações e efeitos de verdade, ao disseminar um saber discursivamente institucionalizado e legitimado sobre o corpo da criança e as trocas afetivas. Embora o material em análise não esteja diretamente ligado ou subordinado ao Governo Federal ou ao MEC, ele não deixa de promover e fazer circular práticas discursivo-sociais que são institucionalizadas, passando a regular os sentidos sobre as trocas afetivas na infância.

\footnotetext{
${ }^{4}$ É relevante destacar que o material em análise ora é apresentado como um livro, ora como umguia que fornece conceitos e diretrizes para prevenir a violência sexual na infância.

${ }^{5}$ Mais informações sobre nossoobjeto de estudo serão apresentadasno item em que retomamos e descrevemos o material de análise e sua proposta.

${ }^{6}$ Ao dizermos Estado, não estamos nos referindo, exclusivamente, ao Governo Federal e seus poderes, mas sim às diversas instituições que individuam o sujeito e que regulam suas práticas discursivas, tal como a instituição escolar.
} 
Tendo em vista que sujeitos e sentidos se constituem mutuamente e que a linguagem não é transparente, ao constituir o sentido por meio de processos discursivos como substituições, omissões, paráfrases, sinonímias, elipses, etc., constitui-se, também, o sujeito e sua relação com o saber, no caso deste estudo: sua relação com o seu corpo e sua sexualidade ${ }^{7}$. Daí a importância de tomarmos esse guia de prevenção da violência sexual como objeto de análise, de forma a extrair da materialidade significante (verbal ou não-verbal) possíveis consequências sociais, políticas $^{8}$ e ideológicas. Trata-se, segundo Orlandi (1996, p. 85), de trabalhar “a opacidade da linguagem, a sua não-evidência, e, com isso, relativizar a relação do sujeito com a interpretação". O dispositivo da AD privilegia a língua enquanto lugar a partir do qual as evidências ideológicas, que são ilusórias, poderiam ser atravessadas (GASPARINI, 2015). Parte-se da descrição da materialidade léxico-semântica do enunciado para fazer emergir sua opacidade, lembrando que a unidade e a transparência nada mais são do que um efeito da inscrição do sentido e do sujeito num universo de estabilidade lógica.

Não estamos afirmando ou sugerindo, a partir das discussões propostas neste estudo, que materiais como o guia de prevenção da violência sexual sejam irrelevantes e que devam ser banidos das instituições. Ratificamos a importância desses materiais para produção do conhecimento e para a disseminação de informações relevantes para a sociedade. $\mathrm{O}$ que estamos propondo é que levemos em conta as relações entre o linguístico e o extralinguístico na produção do sentido que passa sempre pela compreensão singular de cada leitor e pela particularidade da situação de enunciação. Como destaca Orlandi (1996, p. 90), "É preciso se pensar a relação do sujeito com a linguagem como parte da relação do sujeito com o mundo, em termos sociais e políticos”.

Para desenvolvermos o presente estudo, partimos da hipótese de que materiais que se apresenta como guia e que costumam ser de cunho prescritivo e normativo, se

\footnotetext{
${ }^{7}$ Revel (2005, p. 81) retoma o tema da sexualidade nos estudos de Foucault e salienta que este autor “distingue cuidadosamente 'sexo' de 'sexualidade'. Nas palavras de Foucault (apud REVEL, 2005, p. 81), o discurso da sexualidade não se aplicou inicialmente ao sexo, mas ao corpo, aos órgãos sexuais, aos prazeres, às relações de aliança, às relações interindividuais etc. [...]".

${ }^{8}$ Quando nos referimos ao político, pela perspectiva da $A D$, não estamos nos detendo à política partidária ou aos nossos governantes, mas sim ao "político visto como divisão do sujeito" (ORLANDI, 2015, p.189), como contradição inerente ao sujeito de linguagem e ao sentido.
} 
pautam num ideal de transparência da comunicação que, a nosso ver, se mostra inatingível, posto que a contradição e o equívoco são constitutivos do sujeito e da linguagem e que o sentido nunca é fixo, pois sempre pode vir a ser outro (ORLANDI, 1996). A seguir, adentramos algumas noções que se mostram relevantes para ancorar teoricamente a análise do corpus discursivo.

\title{
Sobre o processo de constituição do sujeito e do sentido
}

Sem perder de vista a opacidade do texto e a não transparência da linguagem, a proposta da $\mathrm{AD}$ é "explicitar os mecanismos de funcionamento do discurso. O trabalho do analista de discurso é mostrar como um objeto simbólico produz sentidos, como os processos de significação trabalham um texto" (ORLANDI, 1996, p. 80). Na perspectiva discursiva, não concebemos a língua como um instrumento de comunicação, nem como um sistema fechado em si mesmo, passível de categorização e do controle do sentido por parte do enunciador. Haroche (1992, p. 40) salienta que há uma ambiguidade potencial de todo discurso impossível de ser neutralizada ou apagada. Nas palavras da autora, “com efeito, não é possível dizer tudo e sempre se pode acrescentar um elemento capaz de precisar, modificar, restringir e mesmo contradizer o pensamento...”. Trazendo essas considerações para problematizar guias e/ou cartilhas que buscam 'precisar' um padrão de comportamento a ser seguido, podemos afirmar que a clareza e a transparência pretendidas por tais materiais costumam falhar, pois quando se trata da língua posta em funcionamento, "não há metalinguagem" (PÊCHEUX, [1983] 1997 , p. 53), mas sim efeito metafórico, deslizamento de sentido. Nesse prisma, Pêcheux ([1975] 2014, p. 83) salienta que

\begin{abstract}
a expressão 'instrumento de comunicação' deve ser tomada em sentido figurado e não em sentido próprio, na medida em que esse instrumento permite, ao mesmo tempo, a comunicação e a não comunicação, isto é, autoriza a divisão sob a aparência da unidade, em razão do fato de não se estar tratando, em primeira instância, da comunicação de um sentido.
\end{abstract}

\footnotetext{
${ }^{9}$ Quando houver duas datas, a primeira corresponde à edição original da obra; a segunda, à edição consultada.
} 
A interpretação está diretamente atrelada à produção do sentido. Como sujeitos de linguagem, estamos fadados a tudo interpretar e (re)significar, já que não há uma relação direta entre o homem e o mundo que não passe pela linguagem e por seu funcionamento essencialmente ideológico e metafórico. Orlandi (1996, p. 8o) afirma que não há sentido sem essa possibilidade de deslize e, pois, sem interpretação, já que “toda descrição está intrinsecamente exposta ao equívoco da língua”. O equívoco, na perspectiva da $\mathrm{AD}$, não se iguala ao erro que poderia ser evitado ou contornado com uma reformulação sintática. Em suma, não entendemos o equívoco como um erro a ser corrigido, mas sim como possibilidade de deslizamento do sentido ou do sentido outro. Nas palavras de Orlandi (1996, p. 92), "na posição de analista do discurso, o que fazemos é não negar o equívoco, mas considerá-lo em sua relação com a linguagem, não apagá-lo, mas trabalhá-lo. É o apagamento do equívoco que produz a ilusão de evidência” e, acrescento, da transparência do sentido ou do sentido já-lá, ilusoriamente colado à palavra. Sobre o equívoco próprio à ordem da língua, Pêcheux ([1983] 1997, p. 53) postula que "todo enunciado é intrinsecamente suscetível de tornar-se outro, diferente de si mesmo, se deslocar discursivamente de seu sentido para derivar para um outro". "Esse deslize, próprio da ordem do simbólico, é o lugar da interpretação, da ideologia, da historicidade" (ORLANDI, 1996, p. 81). Daí a importância de nos indagarmos sobre os sentidos que são produzidos a cada gesto de leitura e interpretação de qualquer texto ou materialidade significante. Há, nos recursos didáticos em geral, um sentido intencionado e antecipado pelo autor, mas sentidos outros, por vezes indesejados, podem vir à tona, dependendo da formação discursiva e ideológica com a qual o sujeito leitor se identifica para que as palavras ganhem determinados sentidos. Pêcheux ([1975] 2014, p. 160) salienta que "o sentido de uma palavra, de uma expressão, de uma proposição etc., não existe 'em si mesmo; [...] elas adquirem seu sentido em referência às formações ideológicas”.

Entendendo a interpretação e a leitura como atos simbólicos, como práticas discursivas que produzem intervenção no mundo, tal como propõe Orlandi (1996, p. 84), optamos pelos termos gestos de leitura e de interpretação. Compreendemos a leitura como um acontecimento discursivo sempre inédito, capaz de produzir sentidos outros, inclusive sentidos não antecipados ou previstos por aquele que exerce a função de autor. A partir de uma concepção discursiva de leitura, Coracini (2001, p. 141) 
enfatiza que "[...] ler pressupõe um sujeito que produz sentidos, envolvendo-se, dizendo-se, significando-se, identificando-se”. Assim sendo, o processo de leitura se constitui em um processo de ressignificação constante, diretamente atrelado à posição discursiva, portanto ideológica ${ }^{10}$, do autor e do leitor, bem como ao momento sóciohistórico vivenciado. Com efeito, destaca Orlandi (2015, p. 189),

sujeitos e sentidos se constituem ao mesmo tempo. Mas a maneira como o próprio sujeito se constitui, pela ideologia, e os sentidos, pela inscrição da língua na história, não é transparente, nem para os próprios sujeitos nem para a sociedade. É a isto que chamamos de materialidade do sujeito e dos sentidos.

Fazer emergir a não transparência e a opacidade da linguagem nos parece ser uma tarefa fundamental para sairmos da ilusão de evidência do sentido e para promovermos uma relação mais consequente do sujeito com a linguagem, ao refletirmos sobre os efeitos das práticas discursivas e de determinados gestos de interpretação na subjetividade e na sociedade.

Sobre o processo de constituição do sujeito, Orlandi formula, a partir dos postulados Pecheuxtianos, que "os diferentes modos de individuação do sujeito pelo Estado, através das instituições e discursos, resultam, como sabemos, em um indivíduo ao mesmo tempo responsável e dono de sua vontade, com direitos e deveres, e livre circulação social” (ORLANDI, 2015, p. 190). É a forma sujeito-de-direito e de deveres, dono de sua vontade e responsável por seu corpo, que parece atribuir sentidos ao nosso material de análise. "Para que o sujeito-de-direito possa responder por si, por seus atos, por seu comportamento, é preciso, previamente, tornar o homem uniforme, regular, determinado, predizível, mensurável”... (HAROCHE, 1992, p. 30). Para tanto, há, segundo Pêcheux ([1975] 2014, p. 159), “o processo da interpelação-identificação que produz o sujeito no lugar deixado vazio: 'aquele que...'[...]; e isso sob formas diversas, impostas pelas relações sociais-jurídicas e ideológicas”. Podemos afirmar, com base em Haroche (1992, p. 21), que o poder, o Estado e o direito produzem e determinam o sujeito, por meio de mecanismos individualizantes que controlam e regulam a vida em sociedade. Partindo dessas considerações, poderíamos pensar no guia de prevenção da violência sexual como um mecanismo de individuação a serviço do Estado que, através

\footnotetext{
10 "A ideologia, vista pela perspectiva discursiva, é a responsável, não pela ocultação, mas pelo efeito de evidência, produzido pela interpretação” (ORLANDI, 2015, p. 189).
} 
das instituições e dos discursos que faz circular, regula e normatiza as trocas afetivas na infância? Mais adiante, buscaremos ancorar esse questionamento no material de pesquisa e nas análises propostas.

Sobre o controle do corpo e das trocas afetivas, Revel (2005, p. 30), retomando os estudos foucaultianos, destaca que o controle

é essencialmente uma economia do poder que gerencia a sociedade em função de modelos normativos globais integrados num aparelho de Estado centralizado; trata-se, igualmente, de tornar o poder capilar, isto é, de instalar um sistema de individuação que se destina a modelar cada indivíduo e a gerir sua existência.

Com base nas afirmações anteriores, salientamos que o sujeito e os sentidos resultam de um complexo processo de constituição, embora, afetado pela ilusão de origem do sentido e de evidência discursiva, o sujeito não se dê conta disso. Como nos mostra Pêcheux ([1975] 2014, p. 162),

o funcionamento da ideologia como interpelação dos indivíduos em sujeito (e, especificamente em sujeitos de seu discurso) se realiza através do complexo das formações ideológicas [...] e fornece 'a cada sujeito' sua 'realidade', enquanto sistema de evidências e de significações percebidas - aceitas experimentadas.

O sujeito enunciador acredita estar na origem do sentido que seu dizer produz, quando, na verdade, se inscreve em uma determinada formação discursiva "(e não em outra) para que as suas palavras tenham sentido e isto lhe aparece como 'natural', como sentido lá, transparente" (ORLANDI, 1996, p. 85). Sobre o efeito de transparência da linguagem, Pêcheux ([1975] 2014, p. 160) destaca que "é a ideologia que fornece as evidências que fazem com que uma palavra ou um enunciado 'queiram dizer o que realmente dizem"'. Aprofundar a relação entre a ideologia e os mecanismos de funcionamento do discurso é essencial para que possamos compreender a determinação do sujeito e do sentido. São esses mecanismos e processos discursivos que buscamos descortinar ao longo da análise que se segue.

\section{O material de análise e sua proposta}


O guia de prevenção da violência sexual na infância, que tomamos como objeto de análise, foi desenvolvido em parceria com o Centro de Orientação em Educação e Saúde. Os projetos e iniciativas deste instituto, que promove a formação de profissionais da área de educação e saúde, já receberam diversos prêmios. De acordo com informações encontradas no website deste instituto ${ }^{11}$, trata-se de

[...]uma organização não-governamental, sem fins lucrativos, que atua na defesa dos direitos da criança e do adolescente, com ênfase na Educação Sexual como prevenção primária de violência sexual. Desenvolve ações em políticas de enfrentamento à violência sexual e de promoção da Educação Sexual numa perspectiva emancipatória, entendida como um direito fundamental para o desenvolvimento pleno do indivíduo.

Apesar de ser uma organização não-governamental, o instituto em questão trabalha em parceria com o Estado, sobretudo ao desenvolver políticas específicas para promoção da Educação Sexual. Foucault (1999) reflete sobre o modo como o poder do Estado, por meio de práticas jurídicas, atua e se entranha na vida dos sujeitos, 'normalizando-os'. O Estado, através de suas instituições e dos discursos que faz circular como verdadeiro(s), se vale de técnicas particulares de poder e de 'governamentalidade ${ }^{12}$, produzindo o sujeito individualizado, isolado e responsabilizado. No recorte discursivo acima, observa-se a determinação e a produção do sujeito sob a forma do sujeito de direito. O direito fundamental à Educação, no caso à Educação Sexual, se coloca como primordial para o desenvolvimento pleno do indivíduo (grifo nosso) que passaria a ser o responsável por seu corpo e pela prevenção da violência sexual na infância. Na perspectiva do individualismo, segundo Acserald (2008 apud Orlandi, 2015, p. 194), a razão é um princípio fundamental. Nesta perspectiva do individualismo, enfatiza Orlandi (2015, p. 194), "não há oposição entre indivíduo e sociedade, e o indivíduo deve ter condições para vir a ser o que é, de realizar-se, de pensar por conta própria e de tomar suas decisões”.

\footnotetext{
${ }^{11}$ www.institutocores.org.br

${ }^{12}$ Conceito proposto e discutido por Foucault.
} 
Sobre as atividades desenvolvidos por este instituto, tais como consultoria $e$ projetos, análise e sistematização de informações que fundamentam o trabalho com temas de Sexualidade Humana e Educação Sexual, desenvolvimento de material didático e formação profissional ${ }^{13}$, chamou-nos a atenção o fato de a equipe de trabalho ser composta por profissionais que representam diferentes instituições que, em parceria com o Estado e seu poder centralizador, promovem a gestão da vida em sociedade, são elas: a Escola, o Direito, a Medicina, a Psicologia. Os projetos desenvolvidos pelo instituto são encabeçados por uma pedagoga, três psicólogos, um médico pediatra, uma jornalista e um advogado. O lugar social do qual esses profissionais falam para produzir saber, bem como o poder exercido através de suas práticas discursivo-sociais se materializam e ressoam no material de análise que abordaremos a seguir. Revel (2005, p. 29), retomando a obra “A verdade e as Formas Jurídicas" de Foucault, afirma que

o controle social passa não somente pela justiça, mas por uma série de outros poderes laterais que se articulam (as instituições psicológicas, psiquiátricas, criminológicas, médicas pedagógicas; a gestão dos corpos e a instituição de uma política da saúde; os mecanismos de assistência, as associações filantrópicas e os patrocinadores etc.)

São esses poderes laterais, exercidos por representantes de diferentes instituições, que se articulam no material em análise, com vistas ao controle da violência sexual na infância, à medida que produzem um poder-saber sobre o corpo e as trocas afetivas. A noção de biopolítica como um conjunto de biopoderes que produzem a gestão dos corpos e da vida, segundo os estudos foucaultianos, nos ajuda a compreender a formulação dos enunciados postos no guia em questão. A biopolítica, retoma Revel (2005, p. 26), "por meio dos biopoderes locais - se ocupará, portanto, da gestão da saúde, da higiene, da alimentação, da sexualidade, da natalidade etc., na medida em que elas se tornaram preocupações políticas". Como a gestão da sexualidade, associada à gestão da saúde, se apresenta no livro destinado à prevenção da violência sexual? Que efeitos pode produzir na subjetividade de seus leitores? Que gestos de leitura e interpretação podem suscitar?

\footnotetext{
${ }^{13}$ Informações encontradas no site oficial do Instituto.
} 
Como já dito anteriormente, tomamos como material de análise um guia que se propõe a instruir crianças de 4 a 12 anos de idade a respeito da violência sexual na infância. O livro Pipo e Fifi, que também possui uma versão Pipo e Fifi para bebês de o a 3 anos de idade, já foi traduzido para o Espanhol, Português de Portugal e Inglês. A autora do material, que é pedagoga e especialista em Educação Sexual, também realiza projetos com vistas à formação profissional e ao atendimento de crianças em outros países como: Inglaterra, Espanha, Portugal e Cabo Verde.

Antes de se iniciar a história apresentada no livro, há um recado endereçado aos adultos que farão a leitura desse guia para as crianças. A autora evoca os nomes dos personagens que criou para transmitir sua recomendação inicial: "Fifo, Pipi e Carol recomendam que este livro seja lido na companhia de um adulto bem legal e responsável". Ao término da história, encontramos um recado destinado "aos adultos legais e responsáveis" que reproduzimos abaixo. Há uma determinação jurídica dos enunciados que abrem e finalizam a obra, sobretudo se atentarmos para o deslizamento de sentido(s) que o emprego do vocábulo legais produz ao adjetivar osadultos encarregados de ler e, até mesmo, de explicitar alguns dos sentidos que o guia produz. Recomenda-se, portanto, que o adulto-leitor seja um adulto legal $e$ responsável. O termo adulto legal, além de produzir o sentido de um adulto com qualidades positivas, também nos remete à esfera jurídica, evocando a ideia de um adulto legalmente responsável pela criança. Passemos à análise do recado que, dentre outras coisas, busca esclarecer a proposta do material e o modo como este deve ser abordado pelo adulto-leitor, lembrando que a grande maioria das crianças com 4 anos de idade, faixa etária para a qual o material se destina, ainda não está alfabetizada. 


\section{RECADO AOS ADULTOS LEGAIS E RESPONSÁVEIS}

Você sabia que 1 a cada 5 crianças sofre algum tipo de violência sexual durante a infância?

E isso independe de etnia, cultura,idade, gênero ou classe social. O abuso sexual, na maioria das vezes, é cometido por uma pessoa

da convivência da criança, na qual ela confia e tem sentimentos de afeto.

Este livro é uma ferramenta de proteçāo que explica às crianças a partir de 4 anos conceitos básicos sobre o corpo, sentimentos, convivência e trocas afetivas. De forma simples e descomplicada, ensina a diferenciar toques de amor de toques abusivos, apontando caminhos para o diálogo, proteçāo e ajuda.

Boa comunicaçâo é a chave de tudo. Nunca é cedo demais para a criança aprender esses conceitos, já que o abuso acontece em todas as faixas etárias. Estudos mostram que a informaçăo em assuntos sobre o corpo e a sexualidade tomam a criança menos vulnerável ao abuso sexual e com competência e habilidade para se expressar e buscar ajuda caso esteja sofrendo este tipo de violência.

O tivro pode ser tido aos poucos e relido oportunamente, com ênfase na observaçāo e interpretaçăo das imagens. Durante a leitura, você deve encorajar a criança a falar sobre suas percepçōes, sobre seus sentimentos e suas vontades.

Fonte: Pipo e Fifi: Prevenção de violência sexual na infância (versão online, disponível em: http://www.institutoapicedown.org.br/wp-content/uploads/2017/o4/Pipo_Fifi.pdf)

O primeiro parágrafo, de natureza informativa e genérica, destaca que "o abuso sexual, na maioria das vezes, é cometido por uma pessoa da convivência da criança, na qual ela confia e tem sentimentos de afeto". Tal afirmação produz um efeito de realidade ou verdade, ao fazer circular as formações imaginárias, ou seja, as imagens sócio-historicamente compartilhadas que ditam e definem o padrão do suposto abusador. Contraditoriamente, ao mesmo tempo em que é sugerido que o suposto abusador pode ser alguém em quem a criança confia, na história criada para ajudar a prevenir situações sexualmente abusivas na infância, encontramos a seguinte afirmação, de natureza prescritiva, dirigida às crianças: "Se acontecer algo ruim, conte para um adulto de confiança”. Como já destacado anteriormente, a língua, longe de ser um meio de comunicação controlável ou instrumentalizável, não é transparente nem para o sujeito enunciador nem para a sociedade, dada a constituição do sujeito pela ideologia e a constituição dos sentidos pela inscrição da língua na história (ORLANDI, 2015, p. 189). Assim sendo, diferentes gestos de leitura e de interpretação irão sempre propiciar o deslizamento do(s) sentido(s) que, muitas vezes, não foram antecipados ou desejados por aquele que exerce a função de autor.

Esta ilusão de transparência do sujeito e do sentido parece permear a proposta do material de análise e sua elaboração, tal como sugerem as seguintes afirmações 
encontradas no recado destinado aos leitores: "Boa comunicação é a chave de tudo"; "De forma simples e descomplicada ensina a diferenciar toques de amor de toques abusivos, apontando caminhos para o diálogo, proteção e ajuda” (grifos nossos). A exigência de transparência, clareza e controle dos sentidos parece fundamentar a elaboração de materiais apresentados como guias ou cartilhas ${ }^{14}$ que partem da ilusão de um sentido já-lá, pronto para ser resgatado e totalmente apreendido pelo leitor. Se considerarmos que sujeitos e sentidos se constituem mutuamente, não é possível supor que a interpretação seja unívoca e inequívoca, embora exista a injunção a uma interpretação já legitimada que costuma ser ratificada nas/pelas instituições. Nesse prisma, poderíamos afirmar que a cartilha sempre falha em seu ideal de clareza e objetividade.

Não estamos sugerindo, no entanto, que o tema da violência sexual e da sexualidade não devam ser discutidos com as crianças, mas sim que não devemos apagar ou desconsiderar o equívoco em sua relação com a linguagem e com o complexo processo de significação, uma vez que a linguagem e a comunicação não são transparentes. Quais são os sentidos que a criança atribui ao material lido? Que efeitos são produzidos em sua subjetividade? Esses são alguns dos questionamentos que não podemos perder de vista como pais e educadores, tal como sugere a autora do material em análise: "Durante a leitura você deve encorajar a criança a falar sobre suas percepções, sobre seus sentimentos e suas vontades”, lembrando que esses sentimentos e vontades também ressoam as condições sócio-históricas atuais, bem como as práticas discursivas consideradas como naturais e verdadeiras em nossa sociedade.

Retomando o trecho "De forma simples e descomplicada [o guia] ensina a diferenciar toques de amor de toques abusivos (...)", nos indagamos se seria possível abordar um assunto tão complexo de forma simples. Para a criança e para o adolescente, lidar com a sexualidade ${ }^{15}$ e com as mudanças experienciadas no corpo é

\footnotetext{
${ }^{14} \mathrm{Em}$ busca dos sentidos já dicionarizados e, portanto, institucionalizados, encontramos as seguintes acepções para Cartilha: Ciência ou doutrina; Padrão de comportamento ou maneira de ser (sentido figurado). O material aqui abordado também funciona como ferramenta que ratifica padrões de comportamento em relação à sexualidade.

${ }^{15} \mathrm{O}$ termo sexualidade não se refere, aqui, ao erotismo ou ao ato sexual em si, mas ao papel central da sexualidade no que tange a estruturação da vida psíquica, tal como apontam os estudos de Freud. Em termos foucaultianos, a sexualidade também funciona como um instrumento do biopoder que
} 
algo traumático por excelência, pois provoca um profundo estranhamento. Sobre a distinção entre sexo e sexualidade, Alberti (2010, p. 8-9) nos esclarece que

originalmente, exige-se, de antemão, um enorme esforço do sujeito pelo simples fato de que a adolescência implica um encontro com o sexo - o qual não se reduz à relação sexual propriamente dita, mas, muito antes disso, é o encontro do adolescente com as questões sobre a assunção de um posicionamento na partilha dos sexos. Esse encontro, que não pode ser evitado e do qual nem mesmo o pai pode salvar seu filho, será mais ou menos angustiante de acordo com o sujeito.

Em “Três ensaios sobre a teoria da sexualidade", Freud ([1905] 1996) aborda a origem e os destinos da pulsão sexual, propondo que há pulsão sexual na mais tenra infância. Dito de outro modo, há sexualidade infantil, ao contrário do que prega o discurso do senso comum que acredita que a sexualidade está atrelada à puberdade. Em alguns trechos do material de análise, parece haver uma indistinção entre a noção de sexo e de sexualidade, já que questões relacionadas à organização fisiológica do corpo se fundem e se confundem com situações que retratariam algum tipo de abuso sexual. Daí a importância de uma leitura atenta e de uma escuta singular dos gestos de interpretação da criança. Na ilustração abaixo, a angústia vivenciada diante da sexualidade e do estranhamento em relação ao próprio corpo parece se manifestar na escolha da personagem Fifi que representa o sexo feminino e é retratada como uma simpática monstrinha. $\mathrm{O}$ emprego do diminutivo para se referir à monstrinha parece atribuir certo apreço à personagem. Como a criança significa ou atribui sentidos a esta associação proposta entre a menina, seu corpo e a monstrinha? Que efeitos essa relação pode produzir? Tendo em vista que o sentido passa pela compreensão singular de cada um, bem como pela particularidade da situação de enunciação (quem lê, para quem, em que situação, etc.), mostra-se significativo atentarmos para os sentidos que a leitura desse material e suas imagens podem suscitar nas crianças.

regula a organização fisiológica do corpo e o comportamento sexual, por meio dos discursos e das práticas de "medicina social" (REVEL, 2005, p. 80). O discurso da sexualidade, segundo Foucault (apud REVEL, 2005, p. 81), "não se aplicou inicialmente ao sexo, mas ao corpo, aos órgãos sexuais, aos prazeres, às relações de aliança, às relações interindividuais etc. [...]". 


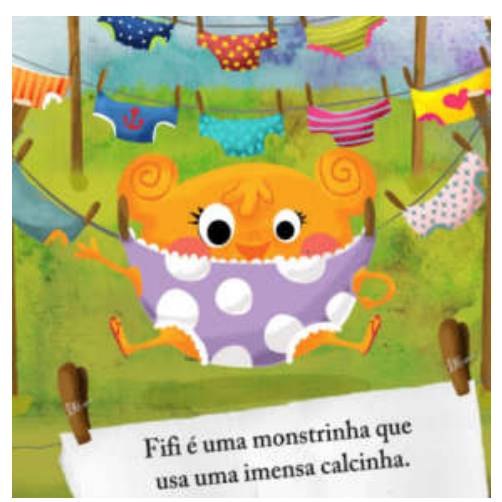

Fonte: Pipo e Fifi: Prevenção de violência sexual na infância (versão disponível em: http://www.institutoapicedown.org.br/wp-content/uploads/2017/o4/Pipo_Fifi.pdf)

Em suma, o material apresenta, primeiramente, as partes do corpo da criança, os toques ou afetos que seriam permitidos, os que seriam proibidos e o que pode ser feito diante de atitudes retratadas como sexualmente violentas ou abusivas na infância. O próprio modo como as informações são veiculadas e condensadas no guia já aponta para uma aproximação e possível indistinção entre a sexualidade relacionada a questões corporais, ao desconhecimento e estranhamento em relação ao próprio corpo e o sexo enquanto ato sexual que, por sua vez, estaria diretamente atrelado à violência. No recorte abaixo, por exemplo, o corpo é posto como algo que a criança deve defender do mal, isto é, de possíveis abusos sexuais. Para tanto, a criança precisaria se munir de informações que supostamente seriam transmitidas por meio de uma comunicação precisa, livre de equívocos e de opacidade.

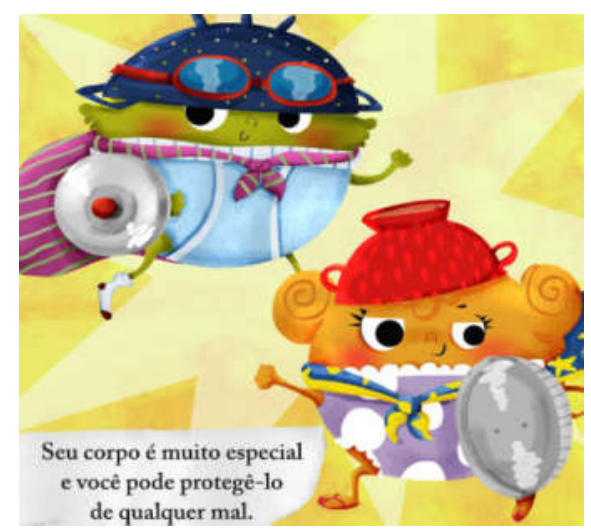

Fonte: Pipo e Fifi: Prevenção de violência sexual na infância (versão disponível em: http://www.institutoapicedown.org.br/wp-content/uploads/2017/o4/Pipo_Fifi.pdf) 
No recado endereçado aos adultos leitores, encontramos a seguinte afirmação: "Estudos mostram que a informação em assuntos sobre o corpo e a sexualidade tornam a criança menos vulnerável ao abuso sexual e com competência e habilidade para se expressar e buscar ajuda caso esteja sofrendo este tipo de violência”. No trecho destacado, a menção aos estudos faz ressoar o discurso da ciência que atribui um efeito de verdade e legitimidade à afirmação posta, ainda que os estudos não tenham sido descritos ou especificados. Em outras palavras, o fato de haver estudos a respeito do tema abordado já é suficiente para sustentar o que é proposto no guia de prevenção. Observa-se, ainda, que o acesso à informação aparece como sinônimo de mudança e de prevenção, embora saibamos que entre a obtenção de informação e a transformação social e subjetiva haja uma certa distância que, por vezes, se mostra intransponível. Em que medida a informação produz transformação? Como educadores, numa época em que o acesso à informação está cada vez mais difuso, precisamos nos atentar para o modo como os alunos incorporam, transformam e/ou se apropriam dessas informações.

No mesmo trecho destinado aos adultos leitores, o emprego de termos como competência e habilidade nos remete à lógica tecnicista, típica da sociedade neoliberal que prega e sustenta a busca por excelência, eficácia e eficiência em todos os setores da vida, não só nos que dizem respeito à prática profissional. No caso do recorte analisado, prega-se a eficácia e habilidade para distinguir toques afetivos e para gerir o próprio corpo. Sobre a presença maciça do neoliberalismo em nossa sociedade, Dardot e Laval (2016, p. 34) postula que o neoliberalismo, enquanto sistema normativo dotado de certa eficiência, "é precisamente o desenvolvimento da lógica do mercado como lógica normativa generalizada, desde o Estado até o mais íntimo da subjetividade”.

Além de explicar quais são as partes do corpo da menina e do menino, por meio dos monstrinhos Fifi e Pipo, que são irmãos na historinha proposta, o material em questão também se propõe a prevenir a violência sexual na infância, conforme destaca o trecho "De forma simples e descomplicada [o guia] ensina a diferenciar toques de amor de toques abusivos, apontando caminhos para o diálogo, proteção e ajuda". Outro questionamento que nos ocorre, tendo em vista a opacidade da linguagem e do sentido, é a (im)possibilidade de categorizar os chamados toques de amor, também tratados na historinha apresentada como toques do sim ou toques permitidos, dos 
toques considerados como abusivos ou toques do não, que deveriam ser evitados. Partindo de uma perspectiva discursiva, acreditamos que toda tentativa de categorização está fadada a falhar, pois não leva em conta a divisão do sujeito, nem do sentido. A categorização proposta no material abordado estabelece uma suposta normalidade para gestão da sexualidade, desde a primeira infância, por meio de um saber discursivamente institucionalizado que ratifica o que deve ser considerado como desvio ou abuso sexual. Foucault (1974-5 [2001, p. 294]) aborda a evolução do controle da sexualidade no interior dos estabelecimentos de formação escolar cristã, sobretudo católica, nos séculos XVII e XVIII. Segundo o autor, há uma insistência discursiva sobre o corpo de prazer,

na tentativa de se apagar, de certo modo, todos esses incêndios verbais que se acendiam com a própria análise do desejo e do prazer, com a própria análise do corpo. Passa-se a borracha, esconde-se, metaforiza-se, inventa-se toda uma estilística da discrição na confissão e na direção de consciência [...].

O mesmo e o diferente parecem funcionar na materialidade posta no guia de prevenção, no qual ainda vislumbramos a presença do discurso religioso cristão no policiamento do corpo e dos prazeres, ao mesmo tempo em que também vislumbramos a presença de práticas neoliberais que organizam a sociedade atual que são postas em funcionamento através do discurso da ciência e do discurso jurídico, que produz o sujeito de direitos e deveres.

Em se tratando de um material destinado para crianças, a presença de imagens é bastante recorrente e marcante. A própria autora do material ressalta que "o livro pode ser lido aos poucos e oportunamente, com ênfase na observação e interpretação das imagens”. Salientamos a importância de se atentar para os gestos de interpretação que as imagens postas no material em questão podem produzir a cada gesto de leitura, tendo em vista que o equívoco também é constitutivo da materialidade não-verbal e, sendo assim, a imagem não diz ou significa por si só, nem produz um sentido único, pois o sentido, seja a partir das palavras ou das imagens, se produz sempre em relação a algo (em relação às suas condições de produção, de enunciação, ao posicionamento discursivo do leitor, às formações imaginárias, etc.). A título de exemplo, destacamos algumas das imagens que aparecem no guia para ilustrar toques do não, considerados como toque abusivos: 

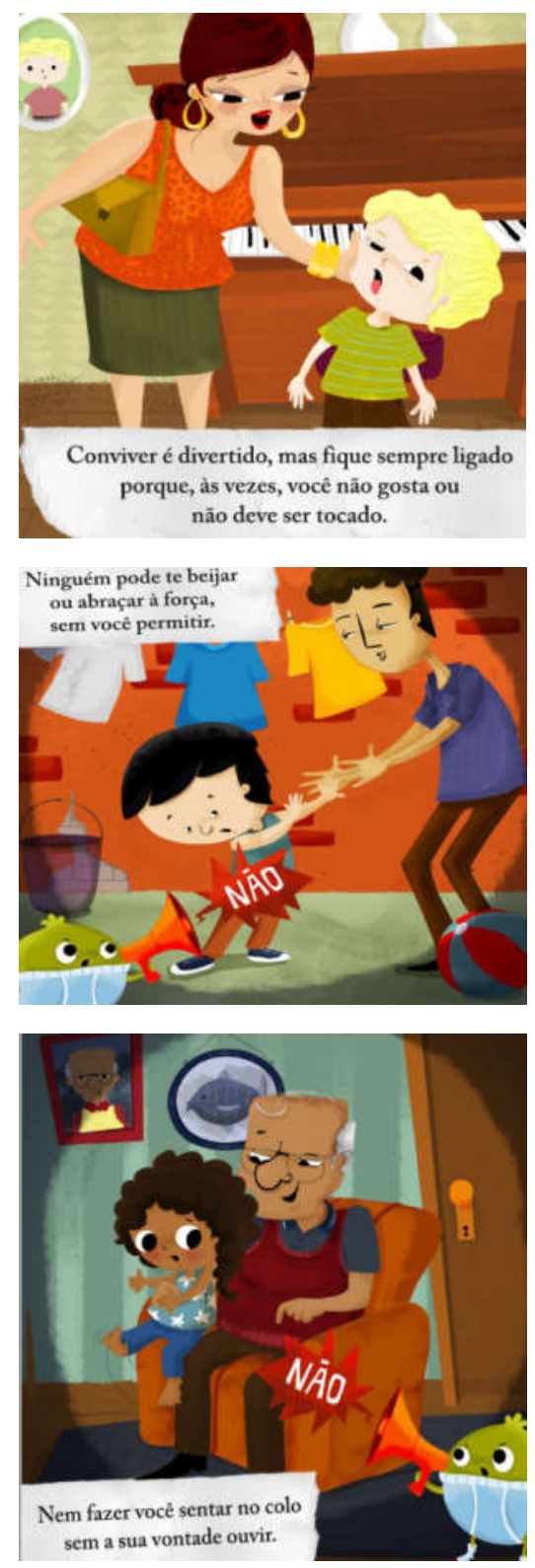

Fonte: Pipo e Fifi: Prevenção de violência sexual na infância (versão disponível em: http://www.institutoapicedown.org.br/wp-content/uploads/2017/o4/Pipo_Fifi.pdf)

Na sequência de imagens e dizeres destacados acima, não podemos pressupor uma relação neutra e de transparência entre as imagens, os enunciados e os sentidos que produzem em seu leitor. A materialidade não-verbal faz funcionar as formações imaginárias que, segundo Orlandi (2015, p. 189), "nos ligam a nossas condições reais de existência”, ao produzir um efeito de reconhecimento da realidade. Nos recortes acima, podemos identificar as imagens que se têm, em nossa sociedade, de alguém capaz de cometer abuso sexual infantil. As imagens do idoso pedófilo e do suposto abusador 
homossexual produzem um efeito de pré-construído para o adulto leitor. Lembrando que o material em questão foi elaborado para crianças a partir dos 4 anos de idade, nos perguntamos como essas imagens poderiam ser interpretadas ou (re)significadas? A criança poderia associar a imagem do idoso retratado como pedófilo com a de seu avô e a do jovem abusador com a de seu irmão ou primo, por exemplo, e passar a imaginálos como abusadores em potencial, independentemente das situações vivenciadas? ${ }^{16}$ Poderia supor, de modo generalizado, que o gesto de se sentar no colo de uma pessoa mais velha e de receber um beijo de alguém do mesmo sexo já se configuraria como ações abusivas a serem evitadas? Como essas possíveis associações incidem na subjetividade da criança? Daí a importância de se considerar o equívoco constitutivo dos sentidos que nunca são fixos e de ouvir os gestos de interpretação singulares das crianças, sob pena de se produzir, ainda que não intencionalmente, uma 'judicialização' das relações de afeto, sobretudo nas relações mais estreitas entre amigos e familiares.

Na primeira imagem destacada acima, embora a cena retratada não seja categorizada como toque do não, a criança também poderia interpretá-la como um gesto abusivo que deve ser evitado. Sobre os dizeres "às vezes, você não gosta ou não deve ser tocado", não gostar de ser tocado de uma certa maneira, como ilustra a primeira imagem da sequência acima, não nos parece ser a mesma coisa nem ter a mesma gravidade de ser tocado de maneira sexualmente abusiva, como buscam ilustrar as demais imagens. Ser informado sobre possíveis abusos sexuais na infância é algo extremamente relevante e necessário, mas nos perguntamos até que ponto "ficar sempre ligado" sobre o modo como as pessoas tocam o corpo da criança e manifestam afeto, inclusive dentro do convívio familiar, poderia levar a um excesso no que diz respeito à gestão do corpo e da sexualidade, que, por sua vez, também afetaria o modo como as relações se dão no espaço social, em especial na escola e na família.

Depois de ilustrar e elencar os toques do sim e os toques do não, o guia destaca, em tom conclusivo, que a criança "tem o direito de dizer não e viver feliz".

\footnotetext{
${ }^{16}$ Sabemos que não são raros os casos em que os familiares mais próximos são os abusadores das crianças. O que estamos destacando e problematizando é o fato de o material em questão circular em diferentes países, culturas, espaços e condições socioeconômicas e familiares. Daí a importância de se relativizar os sentidos que a leitura desse material e de suas imagens pode produzir.
} 


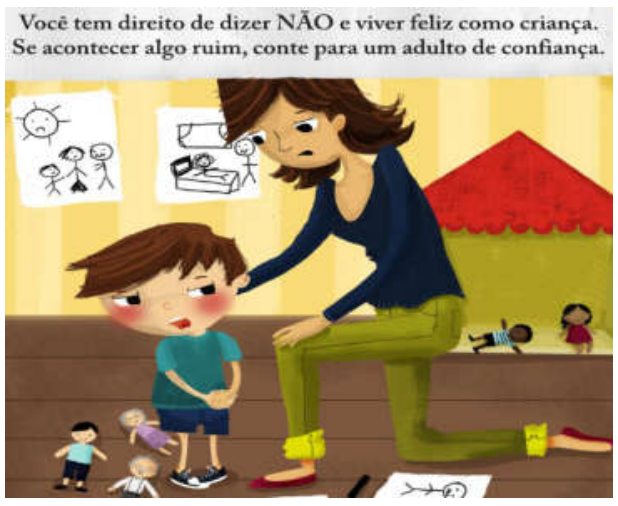

Fonte: Pipo e Fifi: Prevenção de violência sexual na infância (versão disponível em: http://www.institutoapicedown.org.br/wp-content/uploads/2017/o4/Pipo_Fifi.pdf)

Nos enunciados reproduzidos acima, observa-se, mais uma vez, a determinação jurídica na relação do sujeito com a linguagem. O sujeito de direito, que tem o direito de dizer não, após ser informado sobre os supostos toques abusivos retratados na história, passa a responder por si e pela gestão apresentada como saudável e legal de seu corpo e de sua sexualidade. A elipse depois do não, na frase, "você tem o direito de dizer não", produz um efeito de evidência, uma vez que ao término da leitura do material, não se faria necessário retomar ou explicitar ao que ou a quem a criança tem o direito de dizer não.

A história termina com a seguinte imagem e dizeres:

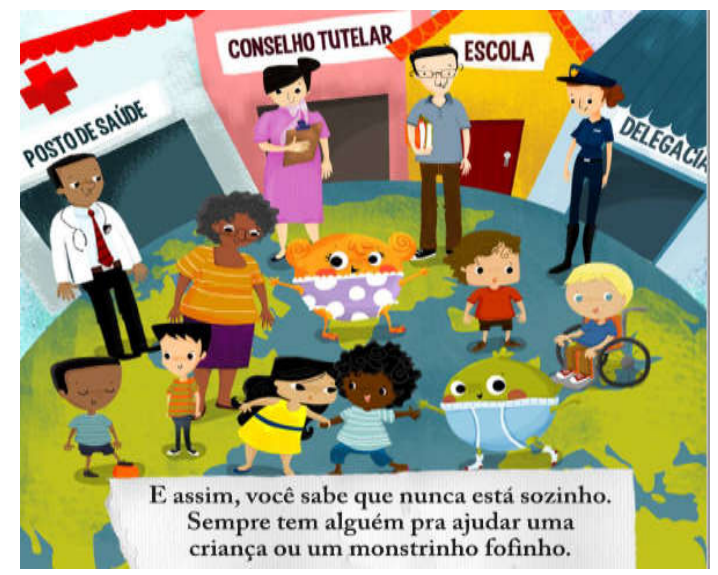

Fonte: Pipo e Fifi: Prevenção de violência sexual na infância (versão disponível em: http://www.institutoapicedown.org.br/wp-content/uploads/2017/o4/Pipo_Fifi.pdf)

É bastante curioso, na ilustração acima, o fato de a solução ou saída para supostos abusos sexuais sofridos pela criança não estar relacionada às pessoas de seu 
convívio, mas sim às instituições retratadas ao fundo da imagem como escola, delegacia e posto de saúde que governam e administram a vida em sociedade, o que pode produzir um efeito de dúvida ou de desconfiança em potencial das pessoas com quem as crianças mais convivem. Lembrando que o material menciona que o abuso, muitas vezes, é cometido por alguém do convívio da criança, poderiam as crianças supor que não podem mais confiar em seus pais e/ou familiares, professores justamente porque são pessoas próximas a elas, independentemente das situações e condições em que vivem? Apenas uma escuta atenta aos diversos gestos de interpretação que esse material pode produzir nas crianças nos ajudaria a endereçar tais questionamentos e a discutir possíveis contradições e dúvidas geradas em seus pequenos leitores-ouvintes.

O recorte acima nos permite entrever o modelo normativo de controle do corpo e das trocas afetivas que é difundido e defendido pelo Estado cujo poder centralizador se pulveriza e se faz presente através dos poderes laterais exercidos por instituições médicas, filantrópicas, pedagógicas, jurídicas, dentre outras. Usando uma terminologia foucaultiana, um conjunto de biopoderes e técnicas normativas e normalizadoras é posto em funcionamento para produzir a gestão do corpo e da sexualidade. A noção de biopoder se atrela à de ideologia, na medida em que essas técnicas normativas, que governam a vida em sociedade, produzem um efeito de evidência e de legitimidade, interpelando os indivíduos em sujeitos de seu discurso e de suas práticas afetivas, através das instituições que exercem e ratificam o poder do Estado.

Por fim, o livro fornece 5 diretrizes que ajudariam o adulto leitor a detectar se a criança, após feita a leitura desse material, “construiu as noções básicas de proteção”: 


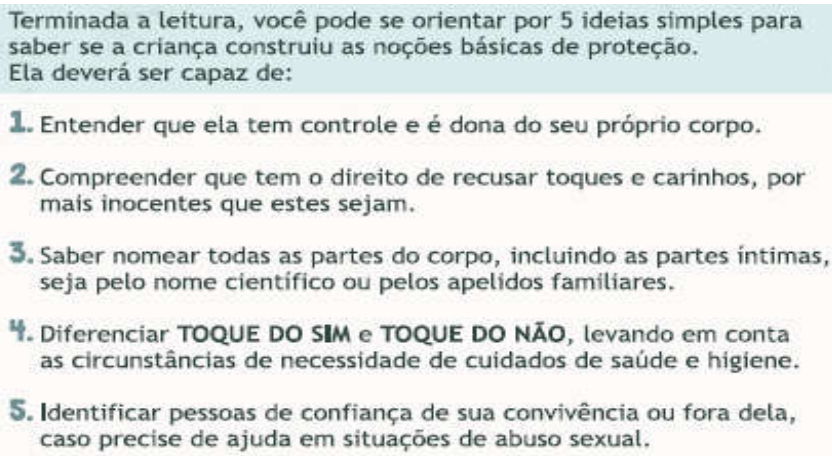

Fonte: Pipo e Fifi: Prevenção de violência sexual na infância (versão disponível em: http://www.institutoapicedown.org.br/wp-content/uploads/2017/o4/Pipo_Fifi.pdf)

$\mathrm{O}$ quadro epistemológico da $\mathrm{AD}$, ao qual nos filiamos teóricometodologicamente, é atravessado e articulado por uma "teoria da subjetividade de natureza psicanalítica” (PÊCHEUX; FUCHS [1975] 2014, p. 160). O sujeito, nesta perspectiva, não é definido como senhor de sua morada, nem como origem primeira e absoluta dos sentidos que seu dizer produz, pois a cisão subjetiva e a determinação inconsciente não são nunca totalmente contornadas ou apagadas. Assim sendo, conceber a criança como alguém que teria pleno controle do seu próprio corpo, sobretudo na tenra idade, nos parece uma tentativa de apagar essa cisão que nos é constitutiva, ao invés de endereçá-la.

No item 4, mais especificamente, é possível observar que a gestão da sexualidade está diretamente atrelada à gestão da saúde e da higiene que se tornaram preocupações políticas sob responsabilidade do Estado e do poder exercido por suas instituições, através dos discursos que nelas circulam. Pelo viés da transparência, que parece orientar a elaboração do material analisado, "o poder procura tornar o sujeito 'sem defesa', procura disciplinar e normalizar sua subjetividade" (HAROCHE, 1992, p. 21). Para além das "circunstâncias de necessidades de cuidados de saúde e higiene", tal como sugere o guia, acreditamos na importância de levarmos em conta as condições específicas de enunciação e de produção dos sentidos, ao se tentar diferenciar os toques afetivos, tendo em mente que a interpretação nunca é unívoca ou inequívoca e está sempre atrelada às condições de sua enunciação.

Acreditamos que um ponto importante a ser considerada pelo adulto, a partir da leitura do referido material, diz respeito aos processos de subjetivação ou aos 
possíveis efeitos subjetivos que os diferentes gestos de leitura e de interpretação podem provocar na criança. Outro questionamento importante a se fazer diz respeito ao item 2 ("compreender que [a criança] tem o direito de recusar toques e carinhos, por mais inocentes que estes sejam"). Ao invés de apenas verificar se a criança compreendeu ou não o seu direito de recusar toques afetivos, direito esse legalmente amparado e instituído, parece nos mais significativo indagarmos como a criança compreende e significa tal direito, em especial quando esses toques afetivos, abusivos ou não, partem de alguém que é da convivência e da confiança da criança. Também convém destacar que a recusa de toques e carinhos inocentes não teria as mesmas consequências jurídicas e subjetivas da recusa dos toques considerados sexualmente abusivos. É importante ter em mente que isso ainda não está claro e bem definido para crianças na tenra idade, que ainda estão aprendendo a nomear o seu próprio corpo e a conviver com os estranhamentos que a relação com o corpo e com a sexualidade produz.

\section{Algumas considerações finais}

A análise aqui proposta mostra o quão complexo é o processo de significação. Não foi nossa proposta, ao longo deste estudo, desqualificar o material aqui analisado, nem responsabilizar seus idealizadores pelas possíveis contradições e sentidos, por vezes indesejados, que este material pode vir a suscitar em seus pequenos leitores, tendo em vista que o equívoco não é neutralizável nem contornável, pois é próprio à ordem da língua. Nossos apontamentos salientam a impossibilidade de transparência da linguagem e do sentido, o que nos leva a olhar para o equívoco e para a possibilidade do sentido outro como algo inerente aos gestos de leitura e de interpretação. Por isso destacamos a importância de interrogarmos o que é posto como claro ou transparente no imaginário social, de modo a possibilitar, para o aluno-leitor, "um espaço politicamente significado em que os sentidos podem ser outros" (ORLANDI, 2015, p. 192). Com base na referida autora, trata-se de ressaltar o caráter social da educação e de interrogar o que é dito, neste imaginário social, sobre trocas 
afetivas e violência sexual na infância, tendo em vista que o guia que tomamos como objeto de análise também reproduz e faz circular esse imaginário. Como postula Pêcheux ([1975] 2014, p. 196), a Análise de Discurso possibilita "um trabalho políticoteórico sobre os 'pré-construídos' e sobre os 'efeitos transversos' que os produziram”.

Sem perder de vista o trabalho com o político, que produz a divisão dos sentidos e do sujeito, nos permitindo ir além do efeito de evidência, é significativo salientarmos que o guia de prevenção da violência sexual se destina às crianças que estariam suscetíveis ao abuso e não aos abusadores cujas ações deveriam ser reguladas e devidamente punidas pelo poder do Estado e de suas instituições. Parece haver um equívoco $^{17}$ ao propor que as crianças, ao serem instruídas pelo material, passem a se responsabilizar por sua proteção diante de supostos abusos e abusadores. A tarefa do Estado, portanto, seria somente a de instruir as crianças e não de convocar, punir e responsabilizar os abusadores. Ao fazê-lo, o Estado acaba se desresponsabilizando em relação à violência sexual que possa vir a ocorrer, uma vez que as instruções e alertas já foram supostamente transmitidos para as crianças. Observa-se que o foco está no abusado e não no abusador que nem sequer é convocado por esta prática discursiva que se pretende oficial e reguladora.

Não se trata de evitar, no espaço escolar, a discussão de questões acerca da sexualidade ou de repreender materiais que ilustrem e enderecem essas questões, mas sim de levar em conta e de provocar, enquanto educadores, outros gestos de leitura e de interpretação; nas palavras de Orlandi (2015, p. 196), “outras posições sujeito com suas formas de (se) significar”. Ao propor a noção de educação social, a referida autora (2015, p. 196) enfatiza que "a escola - enquanto instituição, ou seja, parte do dispositivo de articulação simbólico-político do Estado - é parte desse modo de produção de sentidos”. Para sair do efeito de evidência ou do sentido já-dado, cabe-nos interrogar sobre o modo como o sentido é construído discursivamente, lembrando que a língua, para significar, é afetada pela história e por suas condições específicas de enunciação e de circulação.

\footnotetext{
${ }^{17}$ Agradeço ao parecerista deste texto cuja leitura atenta e pertinentes indagações muito contribui para aprofundar a discussão sobre o equívoco constitutivo do material de pesquisa.
} 


\section{Referências}

ALBERTI, Sonia. O adolescente e o Outro. 3. ed. Rio de Janeiro: Zahar, 2010.

CORACINI, Maria José. Heterogeneidade e leitura na aula de língua materna. In:CORACINI, M.J. \& PEREIRA, A. (Orgs): Discurso e sociedade: práticas em análise do discurso.Pelotas: EDUCAT, 2001, p. 137-155.

DARDOT, Pierre; LAVAL, Christian. A nova razão do mundo: ensaio sobre a sociedade neoliberal. Mariana Echalar Tradução. 1 ed. São Paulo: Boitempo, 2016.

FOUCAULT, Michel. A verdade e as formas jurídicas. Roberto Cabral de Melo Machado e Eduardo Jardim Morais tradução. PUC - Rio de Janeiro: Nau Editora [1973], 1999.

. Os anormais: curso no Collége de France (1974 - 1975). Eduardo Brandão Tradução. São Paulo: Martins Fontes, 2001.

FREUD, Sigmund. Três ensaios sobre a teoria da sexualidade (1905). In: Edição Standard Brasileira das obras psicológicas completas de Sigmund Freud. Vol. VII. Rio de Janeiro: Imago, [1905], 1996, p. 119 - 231.

GASPARINI, Edmundo Narracci. A língua na análise do discurso. In: Revista da Anpoll, n. 39, Florianópolis, Jul./Ago. 2015, p. 62-68.

HAROCHE, Claudine. Fazer dizer, querer dizer. Eni Orlandi tradução. São Paulo: Editora Hucitec, 1992.

ORLANDI, Eni Puccinelli. Interpretação: autoria, leitura e efeitos do trabalho simbólico. Petrópolis: Vozes, 1996.

. Linguagem e educação social: a relação sujeito, indivíduo e pessoa. In: Rua [online]. n. 21 - Volume 2, Novembro / 2015, p. 187 - 199. Consulta no Portal Labeurb Revista do Laboratório de Estudos Urbanos do Núcleo de Desenvolvimento da Criatividade. http://www.labeurb.unicamp.br/rua/

PÊCHEUX, Michel. Semântica e Discurso: uma crítica à afirmação do óbvio. Campinas: Editora da UNICAMP,[1975] 2014.

. O discurso: estrutura ou acontecimento. Eni Orlandi tradução. Campinas: Pontes Editores [1983], 1997. 
; FUCHS, Chaterine. A propósito da análise automática do discurso: atualização

e perspectiva (1975). In: GADET, Françoise; HAK, Tony. (Orgs.) Por uma análise automática do discurso:uma introdução à obra de Michel Pêcheux. Campinas: Editora da UNICAMP. 5. ed., [1975] 2014, p. 159 - 250.

REVEL, Judith. Michel Foucault: conceitos essenciais. Gregolin, M.; Milanez, N.; Piovesani, C. Tradução. São Carlos: Clara Luz, 2005.

Recebido em $07 / 05 / 2018$.

Aprovado em 12/o9/2018. 